\title{
Wheel running in the rat induced by a fixed-time presentation of water*
}

\author{
GLEN D. KING \\ Auburn University, Auburn, Alabama 36830
}

\begin{abstract}
Four female water-deprived albino rats were given free access to a running wheel and food in baseline sessions with water present for the first $375 \mathrm{sec}$ of each daily 100 -min session. In experimental sessions, water was presented intermittently according to a fixed-time (FT) 2 -min schedule, which delivered water on a periodic basis independently of the rat's behavior, resulting in $507.5 \mathrm{sec}$ presentations of the water tube. Food consumption did not vary as a function of the experimental condition, whereas running increased for all Ss during the schedule conditions. Increases in running appeared to be the result of increases in both initiations of running and run-burst lengths.
\end{abstract}

In the past 12 years, an increasing amount of attention has been directed toward unprogrammed behaviors that occur as adjuncts (Falk, 1972) to a schedule of reinforcement or punishment. Schedule-induced polydipsia (SIP), first documented by Falk (1961), may be considered a prototype of such behavior. Falk reported that naive rats receiving $45-\mathrm{mg}$ food pellets on a VI 1-min schedule drank an average of $92.5 \mathrm{ml}$ of water in a 3.17-h session, whereas the average 24-h water intake of a rat in the home cage was about $20-25 \mathrm{ml}$. The phenomenon is labeled schedule-induced because: (1) an intermittent schedule of food reinforcement is a necessary condition for the occurrence of excessive water intake, and (2) excessive water intake declines when the animal is removed from the reinforcement schedule condition. Falk (1972) labeled such responses "adjunctive behaviors," and pointed out that adjunctive behaviors (including aggression, escape, pica, and wheel running) show significant increments when an organism is subjected to a scheduled presentation of reinforcement or noxious stimulus (usually electric shock). It was also noted that common properties are shared by these schedule-induced behaviors, they: (1) occur in the presence of a deprivation state (usually food) in the organism, (2) are excessive and persistent, (3) occur consistently as poststimulus or postreinforcement phenomena, (4) occur as unprogrammed responses independent of specifically reinforced responses, (5) possess sufficient intrinsic motivation to support their own schedule of reinforcement (i.e., the organism will meet arbitrary operant-response requirements in order to obtain the opportunity to perform the adjunctive behavior).

The purpose of this experiment is to demonstrate that scheduled water delivery can induce adjunctive behavior, and to support the hypothesis that the most probable

*This research was supported in part by Public Health Services Research Grants MH-08775 and MH-12025, Robert W. Schaeffer, principal investigator. The experiment comprised part of the author's PhD dissertation. response following the presentation of an intermittent stimulus is the one that will show increments in a response parameter(s). Levitsky and Collier (1968) and Segal (1969) have reported that when rats were deprived of food and exposed to an intermittent food-delivery schedule, excessive "schedule-induced" wheel running developed. In the Segal study, water and running were freely available and, immediately following food delivery, the rats drank and then ran. Since the rat has been considered a postprandial drinker (Kissileff, 1969), drinking would be expected to be a highly probable response following food reinforcement. However, in the present experiment, the rats received water (rather than food) on an intermittent schedule, and food (rather than water) and running were freely available. Preliminary observations of the relationships between eating, drinking, and wheel running led to the conclusion, in this laboratory, that when rats are water-deprived, running in the wheel is the most probable response following the delivery and ingestion of water. Therefore, although both running and eating were available following water delivery, the higher baseline probability of post-water-delivery running led to the prediction that schedule-induced running, rather than schedule-induced hyperphagia, would result from the intermittent water-delivery schedule. Schedule-induced running was defined as an increase in the total amount of running in the schedule condition relative to the baseline condition, and to an increase in running immediately following water delivery relative to the rest of the interval between water deliveries.

\section{METHOD}

\section{Subjects}

The Ss were four naive female albino Dublin SDD/DR rats, approximately $120-150$ days old. The animals were individually housed under conditions of constant illumination, temperature, and humidity. During the experiment, the Ss' water intake was restricted, with access to water only in the experimental apparatus. However, water was made available for a short time 
immediately following the experimental session if an S's weight dropped below $75 \%$ of its weight when water was freely available. Food was freely available to the Ss both in the home cage and in the experimental chambers.

\section{Apparatus}

The experimental chambers were modified Wahmann activity wheels, as described by Schaeffer (1966). Standard relay circuitry was used to program drink-tube deliveries. Water deliveries, half wheel turns, food-magazine contacts, and licks were recorded on Esterline-Angus digital operations recorders, as well as on electromechanical counters. In addition, the fixed-time (FT) 2-min interval between water presentations was divided into eight $15-\mathrm{sec}$ periods, and the number of half wheel turns occurring in each consecutive 15-sec period was totalled across all FT 2-min intervals during each daily schedule condition. The first 15 -sec period included the $7.5 \mathrm{sec}$ of water-tube availability. Wheel running was also continuously tabulated in eight consecutive 15-sec periods during baseline conditions. With termination of tabulation in the eighth 15-sec period, tabulation began again in the first 15-sec period, finally yielding cumulative wheel running in eight 15 -sec consecutive periods across each daily session. Half wheel turns were converted to full wheel turns for all graphical, tabular, and statistical considerations. The amount of water ingested during each experimental session was recorded directly from the $100-\mathrm{ml}$ graduated cylinders. Food intake was measured by weighing the food contents of a small cup that fit into the food magazine before and after the experimental session. The difference was recorded as the amount of food ingested.

\section{Procedure}

The experiment consisted of five phases: (1) a baseline condition, (2) an FT 2-min condition in which water was delivered on a periodic schedule, independently of the organism's behavior, (3) a return to the baseline condition, (4) a replication of the FT 2 -min condition, and (5) a final replication of baseline. In the initial baseline condition, the Ss remained in the experimental chambers for $100 \mathrm{~min}$ with the wheel and food freely available. The drinking tube was available for the first $375 \mathrm{sec}$ of the 100 -min session, after which it was withdrawn for the remainder of the session. Stability in all phases of the experiment was defined as the condition in which the difference between the mean half wheel turns for the last three sessions and the mean for the preceding three sessions was no more than $20 \%$ of the mean of the last six sessions. When baseline wheel running reached stability, the next phase began.

In the second phase of the experiment, the FT 2-min schedule was introduced. Food and wheel running were again freely available. However, water was available for only the first $7.5 \mathrm{sec}$ of every $2-\mathrm{min}$ period. There were 50 presentations of the drinking tube during each 100-min session, and the total water-available time was the same in both the baseline and schedule conditions. When the criterion for stability of running was reached, the second baseline phase (Phase 3 ) was reinstated. When running again reached stability, a replication (Phase 4) of the results obtained in Phase 2 was attempted, followed by a replication (Phase 5) of the baseline results of Phases 1 and 3. As replications of previous phases, Phases 4 and 5 were each restricted to four sessions, which was time enough to duplicate prior results under comparable conditions.

\section{RESULTS AND DISCUSSION}

The mean amount of food ingested, in grams, and the mean full wheel revolutions per session for all experimental conditions across all $\mathrm{Ss}$ is presented in Fig. 1. The mean data presented in Fig. 1 are

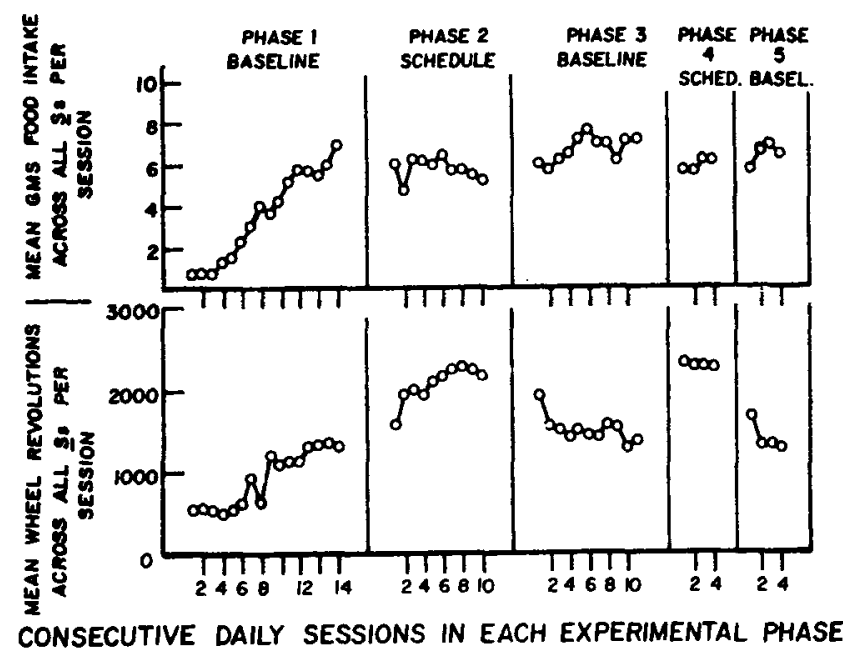

Fig. 1. The mean daily session wheel revolutions and food intake across all Ss in each experimental phase.

representative of all Ss. Total food intake per session was never systematically higher in schedule sessions than in baseline sessions and, for two Ss, there was some indication that eating decreased as running increased. In contrast, running increased in the schedule conditions relative to the baseline conditions for all Ss.

Analyses of variance for repeated measures were conducted for the food-intake and wheel-turns data for all four Ss. Food intakes were not significantly different across conditions, whereas running was significantly greater in the schedule conditions than in the baseline conditions $(p<.01, \mathrm{df}=4)$. These data confirm the prediction that wheel running, rather than hyperphagia, will be induced by the intermittent presentation of water to water-deprived rats.

Figure 2 shows the mean (for all Ss and all sessions) number of full wheel revolutions per session in each consecutive 15 -sec period in the baseline and in the

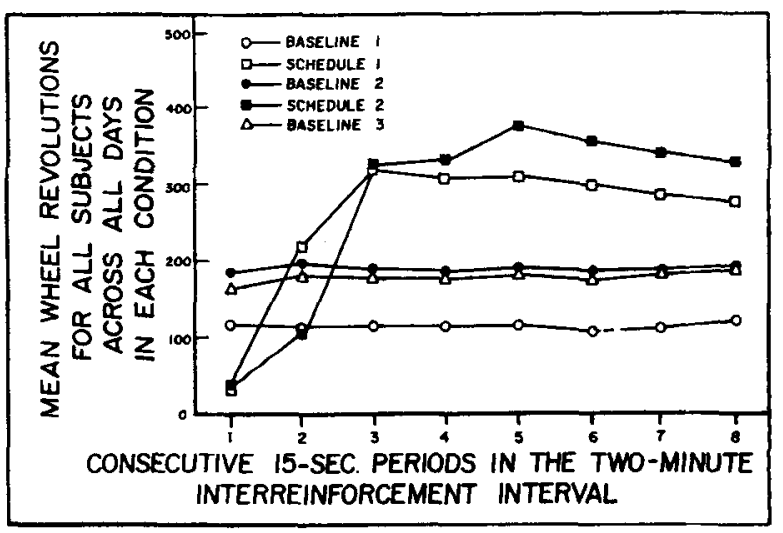

Fig. 2. Mean wheel revolutions across all Ss in each consecutive 15 -sec period during the baseline conditions and in the interval between water presentations during schedule conditions. 
Table 1

Mean Number and Percent of Run Burst Lengths (in Seconds) Across All Animals for the Last Day of Each Baseline and Schedule Condition

\begin{tabular}{|c|c|c|c|c|c|c|c|c|c|c|}
\hline \multirow{2}{*}{$\begin{array}{l}\text { Run Burst } \\
\text { Length (Sec) }\end{array}$} & \multicolumn{2}{|c|}{ Baseline 1} & \multicolumn{2}{|c|}{ Schedule 1} & \multicolumn{2}{|c|}{ Baseline 2} & \multicolumn{2}{|c|}{ Schedule 2} & \multicolumn{2}{|c|}{ Baseline 3} \\
\hline & $\mathrm{N}$ & Percent & $\mathrm{N}$ & Percent & $\mathrm{N}$ & Percent & $\mathrm{N}$ & Percent & $N$ & Percent \\
\hline $1-10$ & 65 & 47 & 69 & 41 & 28 & 30 & 62 & 36 & 44 & 40 \\
\hline $11-20$ & 58 & 42 & 50 & 30 & 36 & 39 & 47 & 27 & 41 & 37 \\
\hline $21-30$ & 13 & 9 & 25 & 14 & 23 & 25 & 33 & 19 & 21 & 19 \\
\hline $31-40$ & 1 & 1 & 9 & 5 & 3 & 3 & 14 & 8 & 3 & 3 \\
\hline $41-50$ & 1 & 1 & 5 & 3 & 1 & 1 & 5 & 3 & 1 & .5 \\
\hline $51-60$ & - & - & 3 & 2 & 1 & 1 & 5 & 3 & 1 & .5 \\
\hline $61-70$ & - & - & 3 & 2 & - & - & 3 & 2 & - & - \\
\hline $71-80$ & - & - & 1 & .5 & 1 & 1 & 1 & .5 & - & - \\
\hline $81-90$ & - & - & - & - & - & - & 1 & .5 & - & - \\
\hline $91-100$ & - & - & 1 & .5 & - & - & 1 & .5 & - & - \\
\hline $101-110$ & - & - & $i$ & .5 & - & - & - & - & - & - \\
\hline $111-120$ & - & - & 1 & .5 & - & - & 1 & .5 & - & - \\
\hline Total & 138 & 100 & 168 & 100 & 93 & 100 & 173 & 100 & 111 & 100 \\
\hline
\end{tabular}

2-min interval between water presentations during the schedule conditions. The mean data in Fig. 2 are respresentative of all Ss; individual Ss deviate from the mean only in the absolute number of wheel turns emitted per condition, but not in the temporal pattern of running between water deliveries. The pattern of running in the schedule conditions was in marked contrast to the pattern of running observed in the baseline conditions, where the probability of running was constant across all 15 -sec periods. Since water was available for 7.5 of the first $15 \mathrm{sec}$ shown in the schedule conditions, and since Ss drank during $80 \%$ to $100 \%$ of water presentations, the low probability of running in the first $15 \mathrm{sec}$ of both schedule conditions can be ascribed to competition from drinking. However, running did not increase to asymptote until the third 15 -sec period, $37.5 \mathrm{sec}$ after the withdrawal of the drink tube, indicating that, while running increased in the schedule conditions, it did not exhibit a clear postreinforcement temporal pattern. This is inconsistent with data pertaining to other schedule-induced behaviors (Falk, 1972). The data suggest that other unmonitored behaviors that competed successfully with running during the post-water-delivery period may have exhibited temporal patterns characteristic of schedule-induced behaviors. The increase in running, which did not occur as a characteristic "postreinforcement" phenomenon, leads to the speculation that the intermittent presentation of water to water-deprived animals produces increments in a number of behaviors in the inter-water interval, consistent with the description of interim activities described by Staddon and Simmelhag (1971). Furthermore, once the Ss were exposed to the schedule condition, subsequent reintroduction of the baseline condition resulted in higher levels of running relative to the initial baseline condition, i.e., the initial baseline for running was never recovered.

An analysis of running bursts was conducted to determine what factors accounted for the increased running during the intermittent reinforcement schedule and to compare temporal distributions of running with drinking in studies on polydipsia. Run bursts were differentiated on the basis of continuous-running time, with a minimal criterion that the animal must have run at a rate of approximately onehalf wheel turn per second. The mean run-burst data, presented in Table 1, indicated that the increase in running during schedule conditions reflected both an increase in the length of bursts and, to a lesser extent, an increase in the frequency of bursts. This is similar to data on polydipsia (Shumake, 1969; King, 1973), where increments in drinking are associated with increases in the frequency of lick bursts.

The data conform to the general paradigm for schedule-induced behaviors, in that the imposition on water-deprived rats of a schedule of water presentations increased the frequency and duration of the response (running) that was initially most probable following the presentation of water. Wheel running induced by water deprivation and a schedule of water presentations is similar to running induced by food deprivation and a schedule of food presentations and to other schedule-induced behaviors, in terms of predictability of occurrence, increments in responding, but not in terms of temporal distributions of responding.

\section{REFERENCES}

Falk, J. L. Production of polydipsia in normal rats by an intermittent food schedule. Science, 1961, 133, 195-196.

Falk, J. L. The nature and determinants of adjunctive behavior. In R. M. Gilbert and J. D. Keehn (Eds.), Schedule effects: Drugs, drinking, and aggression. Toronto: University of Toronto Press, 1972.

King, G. D. A developmental analysis of schedule-induced polydipsia. Psychological R eports, 1973, 32, 1087-1095.

Kissileff, $H$. R. Food-associated drinking in the rat. Journal of Comparative \& Physiological Psychology, 1969, 3, 284-300. Levitsky, D. A. \& Collier, G. Schedule-induced wheel running. Physiology \& Behavior, 1968, 3, 571-573.

Schaeffer, $R$. W. A new device for programming contingencies between drinking, running, and lever-pressing. Journal of the Experim ental Analysis of Behavior, 1966, 9, 529-533.

Segal, E. F. The interaction of psychogenic polydipsia with wheel running in rats. Psychonomic Science, 1969, 14, 141-142, 144.

Shumake, R. A. B. Shedule-induced polydipsia: An analysis of 
licking patterns on $V R, F R$, and $F F I$ food-reinforcement schedules. Unpublished doctoral dissertation. Florida State University, 1969.

Staddon, J. E. R., \& Simmelhag, V. L. The "superstition" experiment: A reexamination of its implications for the principles of adaptive behavior. Psychological Review, 1971 , 1,343 .

(Received for publication September 4, 1973;

2nd revision accepted August 2, 1974.) 